\title{
Evolving Strategy for Surgical Management of Oral Cancer: Present and Future
}

\author{
Young-Hoon $\mathrm{JoO}^{1}$ (i) $\cdot$ Bon Seok $\mathrm{KoO}^{2}$ (i) \\ ${ }^{1}$ Department of Otolaryngology-Head and Neck Surgery, College of Medicine, The Catholic University of Korea, Seoul; \\ ${ }^{2}$ Department of Otolaryngology-Head and Neck Surgery, Chungnam National University College of Medicine, Daejeon, Korea
}

In Korea, oral cancer is one of the most frequent types of head and neck cancers [1]. Recent research revealed that surgical treatment seems to be effective for oral cancer. The surgical treatment consisted of the wide resection of the primary tumor and the neck dissection. However, the effects of oral cancer surgery can have a serious impact on a patient's quality of life and can impair appearance and functional characteristics such as speech, mastication, and swallowing. There have been many advances in oral cancer surgery over the past decades, but clinical debate exists in many areas.

The surgeon's main purpose in the treatment of oral cancer is to achieve proper ablation. To achieve this, the clinically normal border of tissue, i.e., the margin, is contained around the excreted tumor. In the newly revised American Joint Committee on Cancer 8th edition, the concept of depth of invasion (DOI) was introduced in the T classification method. In this issue of Clinical and Experimental Otorhinolaryngology, Joo et al. [2] recommended that tumor thickness should be assessed to ensure adequate deep resection margin of oral tongue cancer, and it should be assessed by palpation, preoperative imaging studies, or by intraoperative ultrasound because it is difficult to evaluate DOI intraoperatively.

The ability to identify tumors by bone invasions that affect prognosis and require more aggressive treatment is still difficult. So there would be a question whether safety margin must be acquired in mandibulectomy for oral cancer. A recent systematic review has concluded that a marginal mandibulectomy would be an appropriate choice for oral cancers adherent to or superficially invading the cortex of mandible, since there are no statistically significant difference in 2- and 5-year local control rates and survivals between marginal and segmental resections in metaanalyses [3]. McGregor and MacDonald [4] reported planning a clinical resection of 5- to $10-\mathrm{mm}$ of unaffected bone around the tumor for oral cancer. In this issue of Clinical and Experimental
Otorhinolaryngology, Joo et al. [2] recommended resection of at least $10 \mathrm{~mm}$ of uninvolved bone in patients with oral cancer, as measured from either macroscopic tumor or suspected bone involvement. Conflicting data exist, but it is thought that true bone invasion has a negative impact on the risk of recurrence and long-term prognosis. However, low significance of the pathologic status of a bone margin on local disease control and survivals may make difficulty in the justification of such safety margin on mandibular resection.

Reconstruction after ablative oral surgery represents an important challenge for the reconstructing surgeon, from both the functional and esthetic aspects of view. Microvascular free flap is the primarily recommended reconstructive method for most of the oral soft tissue defects that need tissue transfer, while local or regional flap methods may be indicated in specific situations. The osteocutaneous free flap is considered the main method for the primary method of mandibular reconstruction because it has consistently provided the best functional and aesthetic results in patients. In the past, the effectiveness of an osteocutaneous free flap during mandibular reconstruction was largely dependent on the surgeon's expertise and decision-making. Computer-aided surgical technology was introduced in the late 2000s, and it includes virtual surgical planning, computeraided design (CAD) and computer-aided manufacturing (CAM), rapid prototyping, and intraoperative navigation-assists in the planning of reconstructive surgery for reducing trial and error and surgical time [5].

\section{CONFLICT OF INTEREST}

No potential conflict of interest relevant to this article was reported.

Copyright (C) 2019 by Korean Society of Otorhinolaryngology-Head and Neck Surgery.

This is an open-access article distributed under the terms of the Creative Commons Attribution Non-Commercial License (http://creativecommons.org/licenses/by-nc/4.0)

which permits unrestricted non-commercial use, distribution, and reproduction in any medium, provided the original work is properly cited. 


\section{ORCID}

Young-Hoon Joo https://orcid.org/0000-0002-1158-0974

Bon Seok Koo https://orcid.org/0000-0002-5928-0006

\section{REFERENCES}

1. Choi HG, Park B,Ahn SH. Untreated head and neck cancer in Korea: a national cohort study. Eur Arch Otorhinolaryngol. 2017 Mar;274(3): 1643-50.

2. Korean Society of Thyroid-Head and Neck Surgery Guideline Task Force, Joo YH, Cho JK, Koo BS, Kwon M, Kwon SK, et al. Guidelines for the Surgical Management of Oral Cancer: Korean Society of Thyroid-Head and Neck Surgery. Clin Exp Otorhinolaryngol.
2019 May;12(2):107-44.

3. Gou L, Yang W, Qiao X, Ye L, Yan K, Li L, et al. Marginal or segmental mandibulectomy: treatment modality selection for oral cancer: a systematic review and meta-analysis. Int J Oral Maxillofac Surg. 2018 Jan;47(1):1-10.

4. McGregor AD, MacDonald DG. Routes of entry of squamous cell carcinoma to the mandible. Head Neck Surg. 1988 May-Jun;10(5): 294-301.

5. Ciocca L, Mazzoni S, Fantini M, Persiani F, Baldissara P, Marchetti C, et al. A CAD/CAM-prototyped anatomical condylar prosthesis connected to a custom-made bone plate to support a fibula free flap. Med Biol Eng Comput. 2012 Jul;50(7):743-9.

Received February 6, 2019

Revised February 27, 2019 Accepted February 27, 2019 